\title{
Development of non-enzymatic cholesterol electrochemical sensor based on CuO(NPs)- Polyaniline-Murexide composite
}

\section{Chedia Ben Ali Hassine}

Université de Monastir: Universite de Monastir

Hamza Kahri ( $\square$ kahrihamza11@gmail.com)

Bilkent Üniversitesi: Bilkent Universitesi https://orcid.org/0000-0003-1768-1511

Houcine Barhoumi

Université de Monastir: Universite de Monastir

\section{Research Article}

Keywords: glassy carbon electrode, polyaniline, murexide, cholesterol detection, impedance, voltammetry

Posted Date: March 10th, 2021

DOI: https://doi.org/10.21203/rs.3.rs-255899/v2

License: (1) This work is licensed under a Creative Commons Attribution 4.0 International License.

Read Full License 


\section{Abstract}

In this study, a novel non-enzymatic sensor based on copper oxide nanoparticles (CuO), polyaniline nanofibers (PANI) and murexide (Mu) modified glassy carbon electrode was developed and used for the detection of cholesterol. Copper oxide nanoparticles were deposited on the glassy carbon electrode through electrodeposition and electrochemical oxidation followed by electrodeposition of PANI-Mu composite. The as prepared CuO-PANI-Mu sensor was characterized using electrochemical, optical and morphological methods such as cyclic voltammetry (CV), impedance spectroscopy (EIS), linear sweep voltammetry (LSV), UV-visible and scanning electron microscopy (SEM). The elaborated composite matrix was used for cholesterol detection employing the impedance spectroscopy method. As a result, good analytical performances were obtained for cholesterol quantification with good stability and high sensitivity $(5575 \Omega / \mathrm{M})$ with a wide linear range from $0.5 \mathrm{nM}$ to $50 \mathrm{mM}$.

\section{Introduction}

Sensors are one of the most developed devices according to their potential applications in several fields like clinical diagnostics, environmental and bioprocess monitoring. Cholesterol is one of the main constituents of mammalian cell membranes as well as cholesterol is a precursor of other biological materials [1]. The detection of cholesterol has received a lot of attention because high cholesterol blood levels can increase risks of heart diseases such as atherosclerosis, high blood pressure and myocardial infraction [2]. As a result, most food producers are obliged to decrease the cholesterol level in food in order to control cardio-diseases. Therefore, there is an increasing demand for sensitive, selective, fast, inexpensive, and robust methods for cholesterol determination in food [3]. The progress in non-enzymatic electrochemical detection of cholesterol was highly accelerated according to the innovative and powerful new sensing material such as nanoparticles and conductive polymers [4-6]. Nanocomposites attracted a lot of attention due to their unique physical properties and wide range of applications. Polymer nanocomposites have captivated scientists considering their novel properties gathered from the successful combination of the characteristics of many constituents into a single material [7]. Conducting polymers such as polyaniline (PANI) are becoming increasingly important. PANI is a relatively air stable organic conducting polymer with high electrical conductivity, good environmental, chemical, electrical stability and easy synthesis $[8,9]$. The use of nanoparticles like Copper oxide (CuO), a versatile semiconductor material, has been attracting the attention due to the commercial demand for electronic devices ${ }^{10}$. Copper oxide has recently been used in several research due to its fascinating properties and wide range of applications such as heterogeneous catalysts, gas sensors, superconductors, lithium ion electrode materials, solar cells and sensors [10-12]. CuO nanostructures have been used as an active material for the elaboration of electrochemical sensors for the reason that they have excellent catalytic and electrochemical properties, low temperature and inexpensive $[13,14]$. The development of inorganic/organic hybrid materials on nano-meter scale have received significant attention thanks to their unique properties $[15,16]$. Overall, the synthesis of hybrid nanocomposites based on polymer and inorganic materials forms a new composite material having synergetic or complementary behaviours of 
the polymer and the inorganic material $[17,18]$. Murexide is the ammonium salt of purpuric acid, it has the appearance of a reddish purple powder and is used in analytical chemistry $[19,20]$. Murexide contributed to the sensor's biocompatibility, better dispersion ability, and hydrophilic characters by introducing more hydroxyl groups. The murexide's hydroxyl groups effectively compensated the positive charge on polymer chains and suppressed the deprotonation processes [21]. In this study, a modified glassy carbon electrode based on polyaniline nanostructures, $\mathrm{CuO}$ nanoparticles and Murexide molecules was developed for the detection of cholesterol.

\section{Material And Methods}

\subsection{Reagents}

Copper sulfate pentahydrate $\mathrm{CuSO}_{4}\left(5 \mathrm{H}_{2} \mathrm{O}\right)$, Potassium monohydrogen phosphate $\left(\mathrm{K}_{2} \mathrm{HPO}_{4}\right)$ and Potassium dihydrogen phosphate $\left(\mathrm{KH}_{2} \mathrm{PO}_{4}\right)$ were purchased from Fluka (Country/Region: French). $\mathrm{KCl}$ (potassium chloride) was purchased from PROLABO. Aniline was purchased from Sigma Aldrich (Country/Region: Tunisia). Cholesterol was purchased from Alfa Aesar (Country/Region: Tunisia). Hydroquinone, sulfuric acid, Triton X-100 and Murexide were purchased from Merck (Country/Region: Tunisia). Chemicals were of analytical grade and were used without further purification. Aqueous solutions were prepared using distilled-deionised water.

\subsection{Apparatus}

Electrochemical data were obtained in a standard three-electrode cell using a potentiostat (DY200 POT Eco-chimie/Maldova) and an Autolab PGSTAT 320N potentiostat (Metrohm/Switzerland). A glassy carbon electrode (GCE, $3 \mathrm{~mm}$ diameter) was used as a working electrode, platinum (Pt) wire was used as counter electrode and an $\mathrm{Ag} / \mathrm{AgCl}(\mathrm{KCl})$ electrode as a reference. Permeability measurements are performed on a rotating working electrode. The UV-Visible measurements were carried out in a spectrophotometers models 6705 UV/Vis (JENWAY/UK). The morphological characterization of the modified electrodes was carried out by a scanning electron microscope JSM 5100 from JEOL/USA using carbon screen printed electrode. Cholesterol solutions were freshly prepared using deionized water and $10 \%$ triton-X-100. Cholesterol detection was performed employing EIS measurement in phosphate buffer $\mathrm{pH}=7.4$.

\subsection{Electrode modification}

Before measurements, the working electrode was polished with $0.3 \mu \mathrm{m}$ alumina powders, sonicated in deionized water, rinsed with water and then electrochemically activated in a $0.5 \mathrm{~mol} . \mathrm{L}^{-1} \mathrm{NaOH}$ solution at a scan rate of $50 \mathrm{mV} . \mathrm{s}^{-1}$ using repetitive cyclic potential sweeps in the range of 0.6 to $1.2 \mathrm{~V}$. Figure 1 shows the different steps adopted to elaborate the modified electrode. In brief, the electrode was dried 
before use. The Cu nanoparticles were electrodeposited on the surface of the electrode at a constant potential of $-0.6 \mathrm{~V}$. Following this step, in order to obtain copper oxide nanoparticles $\left(\mathrm{Cu}_{\mathrm{x}} \mathrm{O}\right)$ (Figure $2 \mathrm{~A}$ and $2 \mathrm{~B}$ ), cyclic voltammetery was performed in $\mathrm{NaOH}$ solution $(0.1 \mathrm{M})$ at the applied potential range from -0.5 to $0.3 \mathrm{~V}$ with a scan rate of $50 \mathrm{mV}$.s -1 for 40 cycles [22]. An electrolyte containing $\mathrm{H}_{2} \mathrm{SO}_{4}$ and aniline was used for the electrodeposition of PANI nanofibers on the electrode [23]. PANI-Mu composite was prepared by chronoamperometry at $\mathrm{U}=0.85 \mathrm{~V}$ versus SCE for $1500 \mathrm{~s}$ in $1.00 \mathrm{M} \mathrm{H}_{2} \mathrm{SO}_{4}$ solution containing $0.025 \mathrm{M}$ aniline and $0.00125 \mathrm{M}$ murexide.

\section{Results And Discussion}

\subsection{Electrode characterization}

The characterization of bare and modified GC electrodes was investigated by cyclic voltammetry (CV), impedance spectroscopy (EIS), linear sweep voltammetry (LSV) measurements and scanning electron microscopy (SEM). In order to characterize the formation of the composite layer on the GC electrode surface, cyclic voltammograms were applied in the presence of hydroquinone $10^{-3} \mathrm{M}$ in phosphate buffer solution ( $\mathrm{Pbs}$ ) at $\mathrm{pH}=7,4$. Figure 3 shows the cyclic voltammograms recorded for the modified and the bare electrodes. The electron transfer is more efficient at modified electrodes if compared with the bare GC electrode. An increase in anodic and cathodic current response is observed after electrode modification indicating that the modified electrode surface was electrochemically active. The EIS was employed in order to investigate the modification effect of GC electrodes surfaces by the composite film. Figure 4A represents typical Nyquist plots for bare GC, GC/Cu(NPs), GC/CuO(NPs), GC/CuO(NPs)/PANI and GC/CuO (NPs)/PANI/Mu electrodes. The Nyquist plots of the bare GC represents at low frequency a straight line with a very small semi-circle at high frequency region. On the other hand, the Nyquist plots of the modified electrodes represents a semi-circle at high frequency region, which is related to higher charge transfer resistance $\left(R_{C t}\right)$ than it was estimated for the bare GCE. This change indicates the passivation of the GC electrode. To simulate the Nyquist plots a standard randles equivalent model circuit was used to estimate the analytical parameters as presented in Figure 4B. The proposed equivalent circuit includes the solution resistance $\left(R_{S}\right)$, the charge transfer resistance $\left(R_{C t}\right)$, the Warburg resistance $\left(W_{\mathrm{o}}\right)$ and the constant phase element (CPE). The experimental impedance values are coupled with Randles equivalent circuit simulation using Nova software. The covered electrode area was calculated using the relation given by Eq.(1) [23-25].

$\boldsymbol{\theta}=\mathbf{1}-\frac{\boldsymbol{R}_{c t}^{\circ}}{\boldsymbol{R}_{c t}}$

Where $R_{0 c t}$ is the charge transfer resistance of the bare $G C$ electrode and $R_{C t}$ is the charge transfer resistance of the modified electrode. The obtained results from Eq.(1) are gathered in Table 1. It was demonstrated that EIS signal is equivalent to $86 \%$ coverage of the GC electrode surface. In fact, when the electrode modification was performed, a dense and better-packed layer of $\mathrm{CuO}(\mathrm{NPs}) / \mathrm{PANI} / \mathrm{Mu}$ was 
established. Therefore, it could be concluded that nanoparticules were intercalated in the conducting polymer film. The permeability $P_{m}$ of the elaborated films under optimal conditions was investigated using a rotating disk electrode (RDE) as shown in Figures $5 \mathrm{~A}$. The rotating disk voltammograms were recorded for the modified electrodes at different rotation rates in an aqueous solution of hydroquinone as electroactive permeant and compared to the results obtained from a bare glassy carbon electrode. The calculation was done according to the equation introduced by Gough and Leypoldt (Gough and Leypoldt, 1979; Gough, 1980). The equation relates the variation of limiting current $i_{\lim }$ with the mass transport for a functionalized rotating disk electrode [26]. $P_{m}$ was calculated using this equation:

\section{$\frac{1}{i_{l i m}}=\frac{1}{0.62} \times n \times F \times A \times D_{S}^{2 / 3} \times C^{0} \times v^{-1 / 6} \times w^{1 / 2}+\frac{1}{n F} P_{m} \times A \times C^{0} \quad \mathrm{Eq}(2)$}

Where, $\mathrm{n}$ is the number of electrons transferred, $\mathrm{F}$

is the Faraday constant, $A$ is the electrode radius, $D$ is the diffusion coefficients for the substrate in the bulk solution, $\mathrm{C}$ is the hydroquinone concentration, $\mathrm{v}$ is the kinematic viscosity of the solution and $\omega$ is the rotation rate of the RDE. The plot of $1 / \mathrm{i}_{\lim }$ versus $\omega 1 / 2$ presents a linear behavior with a positive intercept that depends on the permeability $P_{m}$ of the film (Figure 5B). Permeability values of 0.0039 and $0.0027 \mathrm{~cm} \cdot \mathrm{s}^{-1}$ were calculated for the GC/CuO(NPs)/PANI and the GC/CuO(NPs)/PANI/Mu electrodes respectively. UV visible spectroscopy was also done in order to evaluate the optical activity of the developed matrix. Figure 6 shows the spectra of the PANI layer containing two distinctive peaks at 326 $\mathrm{nm}$ and $644 \mathrm{~nm}$ which are attributed to $\pi-\pi^{*}$ and polaron- $\pi^{*}$ transitions respectively [27]. The UV-visible spectra of the composite film presents three distinctive peaks localized at $259 \mathrm{~nm}, 292 \mathrm{nnm}$ and $452 \mathrm{~nm}$. From literature [15] and Figure 6, it is affirmed that the characteristic peaks of PANI, Mu and CuO(NPs) appeared in the $\mathrm{CuO}(\mathrm{NPs}) / \mathrm{PANI} / \mathrm{Mu}$ composite. Moreover, peaks of polyaniline, $\mathrm{CuO}$ nanoparticles and Murexide at nanocomposite are obviously shifted. It indicates that insertion of $\mathrm{CuO}$ nanoparticles has an effect of doping the conducting polyaniline. This effect should owe to an interaction at the interface of polyaniline and $\mathrm{CuO}$ nanoparticles. The SEM images of bare GC, SPCE/CUO(NPs), SPCE/CuO(NPs)/PANI and SPCE/CuO(NPs)/PANI/Mu electrodes surfaces are recapitulated in Figure 7. As it can be seen from Figure 7, either bare or modified GC electrode surfaces are different from each other. Figure 7 (b) shows the formation of Cuo nanoparticules on the electrode surface. In previous work, the same procedure of deposition was investigated to elaborate $\mathrm{CuO}$ nanoparticules and confirm the formation of nano-copper [28]. The SEM image in Figure 7( $c$ and d) shows that polymeric layer is uniformly distributed on the GC electrode surface. The layer is composed of PANI nanofibers as it can be seen in Figure 7 and as discussed by Haibin Zhang and all [29]. They estimate that the applied potential resulted in different PANI morphologies. This phenomenon can be attributed to the decomposition of PANI controlled by potentials. As we know, the decomposition of PANI occurred simultaneously with the polymerization and there is a competition between the polymerization and the decomposition. When the applied potentials reached $1.00 \mathrm{~V}$ versus SCE, the decomposition of PANI was not negligible. However, in present experiments, the applied potentials did not exceed $0.85 \mathrm{~V}$ versus SCE, and the decomposition of PANI can be neglected. 
Therefore, the PANI nanofibers can be obtained easily [29]. From the SEM image, we can observe better fibers using murexide molecules.

\subsection{Electrochemical performances of the sensing matrix for cholesterol quantification}

The deposited CuO(NPs)/PANI/Mu composite layer was used for cholesterol detection using electrochemical impedance spectroscopy measurements (Figure 8). EIS parameters was calculated using NOVA software by fitting the obtained diagrams (Table 2). An increase in charge transfer resistance $\left(R_{C t}\right)$ is observed with the increase of cholesterol concentration on the electrode surfaces. We can also observe a decrease in Warburg values with increasing cholesterol concertation. These changes in impedance parameters indicate the electrode passivation. A significant increase in the charge transfer resistance as a function of cholesterol concentration is observed. The calculation of the surface coverage of the electrode after each addition shows an increase in the covered electrode surface from $9 \%$ to $83 \%$. This increase proves that cholesterol molecules adheres to the surface of the electrode and increases its concentration in the solid-liquid interface. The cholesterol adhesion on the electrode surface is probably due to its hydrophobic property [30]. Figure 9 shows the plot of $R_{c t}$ as a function of -log[cholesterol]. The modified electrode showed a linear relationship between the charge transfer resistance and the cholesterol concentration in the range from $50 \mathrm{mM}$ to $0.5 \mathrm{nM}(\mathrm{R}=0.9928)$. The deposited layer presents a good sensitivity of $5575 \Omega / \mathrm{M}$ for cholesterol detection. These results indicated that the modified electrode has excellent ability for non-enzymatic detection of cholesterol if compared with previous reports as shown in Table 3. Selectivity is an important parameter for non-enzymatic cholesterol sensor. It is well known that ascorbic acid (AA), uric acid (UA) and glucose interfere with the detection of cholesterol [31]. Therefore, in this study, concentrations of these molecules are 10 times higher than cholesterol concentration. The response of the sensor was recorded in the sample solution containing 10${ }^{5} \mathrm{M}$ of cholesterol. The Figure 10 summarize the results obtained indicating a small variation of the charge transfer resistance in presence of the studied interfering compounds. To check the applicability of the fabricated cholesterol sensor, the amount of cholesterol in milk samples was determined. Specifically, milk samples were diluted with pbs $(0.1 \mathrm{M})$ and a known cholesterol concentration was added to the solution. No further treatment of the sample was required. The obtained results are summarized in table 4 , which indicates that the elaborate sensor show a good detection of cholesterol in milk samples.

\section{Conclusion}

A CuO(NPs)/polyaniline/murexide nanocomposite deposited onto a glassy carbon electrode was used to investigate the non-enzymatic detection of cholesterol. The SEM analysis showed that CUO nanoparticles were incorporated onto the polyaniline-murexide composite. The electrochemical response for cholesterol quantification was evaluated by Impedance spectroscopy method. The non-enzymatic sensor demonstrates a high sensitivity and good stability in a wide range of concentrations from $1 \mathrm{nM}$ to $1 \mathrm{mM}$. 
The developed bioanalytical system was successful applied for cholesterol determination in milk with high recovery and selectivity.

\section{Declarations}

\section{Conflicts of interest}

There are no conflicts of interest to declare

\section{Acknowledgements}

Authors would like to acknowledge BRF-2017-D4P1/ Tunisia project (No. 12Mag088), and the Ministry of Higher Education and Scientific Research of Tunisia (LR11ES55). H.K thanks to the Scientific and Technological Research Council of Turkey (TUBITAK) for the fellowship.

\section{References}

[1] Y.Lee, J.Park, , biosens. bioelectron. 26, 1353 (2010). https://doi.org/10.1016/j.bios.2010.07.048

[2] M.Srivastava, S. K. Srivastava, N. R. Nirala, R.Prakash, Anal. Method. 6, 817 (2014). DOI:

10.1039/C3AY41812J

[3] K. Derina, E. Korotkova, Y. Taishibekova, L. Salkeeva, B. Kratochvil, J. Barek, Anal. Bioanal. Chem. 410, 5085 (2018). https://doi.org/10.1007/s00216-018-1164-x

[4] Li, G., Zeng, J., Zhao, Z. Wang, C. Dong, J. Liang, Z. Zhou, Y. Huang, J. Nanopart. Res. 162, 16 (2019). https://doi.org/10.1007/s11051-019-4602-6

[5] Y.Zhang,Y.N.Wang, X.T.Sun, L.Chen, Z.R.Xu, Sens. Act. B Chem. 246, 126 (2017).

https://doi.org/10.1016/j.snb.2017.02.059

[6] S.Gilbert, H.K.Jeong, P.A.Dowben, chem. Phys. lett., 687, 226 (2017).

https://doi.org/10.1016/j.cplett.2017.09.024

[7] M.A. Chougule, S. Sen, V.B. Patil, Synth. Met., 162, 1603 (2012).

https://doi.org/10.1016/j.synthmet.2012.07.002

[8] M.J. Sailor, E.J. Ginsburg, C.B. Gorman, A. Kumar, R.H. Grubbs, N.S. Lewis, Science., 249, 1149 (1990).

DOI: $10.1126 /$ science. 249.4973 .1146

[9] S.L. Patil, S.G. Pawar, M.A. Chougule, B.T. Raut, P.R. Godse, S. Sen, V.B. Patil, Int J Polym Mater. 61, 820 (2012). https://doi.org/10.1080/00914037.2011.610051

[10] Y.F. Lim, J.J. Choi, T. Hanrath, J Nanomater. 6, 6 (2012). https://doi.org/10.1155/2012/393160 
[11] X.M. Miao, R. Yuan, Y.Q. Chai, Y.T. Shi, Y.Y.Yuan, J. Electroanal. Chem. 612, 167 (2008). https://doi.org/10.1016/j.jelechem.2007.09.026.

[12] G. Ren, D. Hu, E.W.C. Cheng, M.A. Vargas-Reus, P. Reip, R.P. Allaker, Int. J.Antimicrob.Agents. 33, 590 (2009). https://doi.org/10.1016/j.heliyon.2019.e01878

[13] G. Zhu, H. Xu, Y. Xiao, Y. Liu, A. Yuan, X. Shen., ACS Appl. Mater.Interfaces. 4, 751 (2012). https://doi.org/10.1021/am2013882

[14] P. Deka, B. J. Borah, H. Saikia, P. Bharali., The Chemical Record. 19, 173 (2019). https://doi.org/10.1002/tcr.201800055

[15] H. Razmi, H.Nasiri, R. M., Microchim Acta 173, 64 (2011). DOI 10.1007/s00604-010-0527-6

[16] V. Gautam, K. P. Singh, V. L. Yadav, Anal. Bioanal. Chem. 410, 2181 (2018). https://doi.org/10.1007/s00216-018-0880-6.

[17] C. Sanchez, B. Julian, P. Belleville, M. Popall, J. Mater. Chem. 15, 36 (2005). https://doi.org/10.1039/B509097K

[18] A. Rengaraj, Y. Haldorai, Ch.H. Kwak, S. Ahn, K.J. Jeon, S. H. Park, Y.K. Han , Y . S. Huh, J. Mater. Chem. B. 3, 6309 (2015). DOI: 10.1039/C5TB00908A

[19] M. S. Masoud, Kassem T. S. , Shaker M. A., Ali A. E, J. Therm. Anal. Calorim. 84, 555 (2006). https://doi.org/10.1007/s10973-005-9991-3.

[20] K.R. Mahanthesha, B.E. Kumara Swamy, Umesh Chandra S. Sharath Shankar, K.V. Pai, J. Mol. Liq. 172, 124 (2012). https://doi.org/10.1016/j.molliq.2012.05.015.

[21] P.Mn Woi, P. M. F. Lorestani, M.R. Mahmoudian, Y. Alias, Sensor Actuator B Chem. 209, 108 (2015). https://doi.org/10.1016/j.snb.2014.11.072.

[22] H. Zhang, J.Wang, Z.Wang, F. Zhang, S. Wang, Synthetic Metals. 159, 281 (2009). https://doi.org/10.1016/j.synthmet.2008.09.015.

[24] R.P. Janek, W. R. Fawcett, Langmuir. 14, 3018 (1998). https://doi.org/10.1021/la970980+.

[25] H. Barhoumi, A. Maaref, M. Rammah, C. Martelet, N. Jaffrezic-Renault, C. Moustyc, S. Cosnier, E. Perezd, I. Rico-Lattes, Biosensor Bioelectron. 20, 2323 (2005). https://doi.org/10.1016/j.bios.2004.10.010.

[26] D. M. Jundale, S. T. Navale, G. D. Khuspe, D. S. Dalavi, P. S. Patil, V. B. Patil, J Mater Sci: Mater Electron. 24, 3535 (2013). https://doi.org/10.1007/s10854-013-1280-5.

[27] L.W.Zhi, L.Y.Qin, Sensor Actuator B. 141, 153 (2009). https://doi.org/10.1016/j.snb.2009.05.037. 
[28] H. Zhang, J. Wang, Z. Wang, F. Zhang, S.Wang, Synthetic Metals. 159, 281 (2009). https://doi.org/10.1016/j.synthmet.2008.09.015.

[29] N. Agnihotri, A. D. Chowdhury, A. De, Biosens. Bioelectron. 63, 217 (2015). https://doi.org/10.1016/j.bios.2014.07.037.

[30] S. Aravamudhana, A.Kumar, S. Mohapatra, S. Bhansali, Biosens. Bioelectron. 22, 2294 (2007). https://doi.org/10.1016/j.bios.2006.11.027.

[31] Md. A. Ali, P. R. Solanki, M. K. Patel, H. Dhayani, V. V. Agrawal, R. John, B. D. Malhotra, Nanoscale. 5, 2891 (2013). https://doi.org/10.1039/C3NR33459G.

[32] A.Rengaraj, Y.Haldorai, C.H. Kwak, S.Ahn, K.J. Jeon, S. H. Park,Y.K. Han, Y. S. Huh, J. Mater. Chem. B 3, 6309 (2015). https://doi.org/10.1039/C5TB00908A.

[33] N. Agnihotri, A. D. Chowdhury, A. De, Biosens. Bioelectron. 63 , 217 (2015).

https://doi.org/10.1016/j.bios.2014.07.037.

[34] Y.Huang, L.Cui, Y.Xue, S.Zhang, N.Zhu, J.Liang, G.Li, MAT SCI ENG C. 77, 8 (2017). https://doi.org/10.1016/j.msec.2017.03.253.

[35] A.Mondal, N.R. Jana, Chem. Commun. 48, 7318 (2012). https://doi.org/10.1039/C2CC33410K.

[36] M. Martín, P. Salazar, R. Álvarez, A. Palmero, C. L.Santos, J.L. G.Mora, A.R.G.Elipe, Sensor Actuatos B. 240, 45 (2017). https://doi.org/10.1016/j.snb.2016.08.092.

[37] A. Safavi, F. Farjami, Biosens. Bioelectron. 26, 2552 (2011).

https://doi.org/10.1016/j.bios.2010.11.002.

\section{Tables}

Table 1: Simulation parameters of the modified Electrode using Nyquist diagrams. The used circuit is [(R (Q [RW]].

\begin{tabular}{|l|r|r|l|}
\hline Matrix & $\mathrm{R}_{\mathrm{S}}(\boldsymbol{\Omega})$ & $\mathrm{R}_{\mathrm{tc}}(\boldsymbol{\Omega})$ & $\boldsymbol{\Theta} \%$ \\
\hline Bare GCE & 103.61 & 177.43 & - \\
\hline GCE/Cu NPs & 109.59 & 541.49 & 67 \\
\hline GCE/CuO NPs & 105.66 & 432.97 & 59 \\
\hline GCE/CuO NPs/PolyAN & 111.62 & 823.01 & 78 \\
\hline GCE/CuO NPs/PolyAN+Mu & 108.01 & 1275.9 & 86 \\
\hline
\end{tabular}

Table 2: Electrochemical parameters for modified electrode at different temperature, obtained from the analysis of impedance data with the equivalent circuit $[(\mathrm{R}(\mathrm{Q}[\mathrm{RW}]]$. 


\begin{tabular}{|c|c|c|c|c|c|c|}
\hline [Cholesterol] $(\mathrm{M})$ & $\mathrm{R}_{\mathbf{s}}(\boldsymbol{\Omega})$ & $\mathrm{CPE}(\mu \mathrm{F})$ & $\mathbf{N}$ & $\mathrm{R}_{\mathrm{tc}}(\mathrm{K} \Omega)$ & $\mathrm{W}(\boldsymbol{\mu F})$ & $\boldsymbol{\Theta} \%$ \\
\hline 0 & 109.01 & 16.457 & 0.75748 & 6921.4 & 491.94 & 0 \\
\hline $10^{-9}$ & 114.51 & 12.937 & 0.80394 & 7627.1 & 402.94 & 9 \\
\hline $5 \times 10^{-9}$ & 112.88 & 12.637 & 0.80695 & 8835.4 & 408.95 & 21 \\
\hline $10^{-8}$ & 112.6 & 12.376 & 0.80900 & 10954 & 365.48 & 37 \\
\hline $5 \times 10^{-8}$ & 109.99 & 12.481 & 0.80364 & 12230 & 32028 & 43 \\
\hline $10^{-7}$ & 110.96 & 12.001 & 0.80577 & 13835 & 285.41 & 50 \\
\hline $5 \times 10^{-7}$ & 111.88 & 11.307 & 0.81149 & 15442 & 248.36 & 55 \\
\hline $10^{-6}$ & 112.44 & 10.733 & 0.81772 & 16836 & 220.23 & 59 \\
\hline $5 \times 10^{-6}$ & 113.23 & 10.21 & 0.82348 & 20264 & 186.26 & 66 \\
\hline $10^{-5}$ & 114.38 & 9.8692 & 0.82749 & 23151 & 153.32 & 70 \\
\hline $5 \times 10^{-5}$ & 74.918 & 11.495 & 0.78120 & 31405 & 189.1 & 78 \\
\hline $10^{-4}$ & 68.312 & 11.244 & 0.78147 & 35511 & 127.04 & 80 \\
\hline $5 \times 10^{-4}$ & 86.688 & 10.545 & 0.79806 & 38507 & 92.123 & 82 \\
\hline $10^{-3}$ & 98.762 & 10.046 & 0.81060 & 41530 & 66.511 & 83 \\
\hline
\end{tabular}

Table 3: Comparison of the results of the present study with previous reports for cholesterol sensing.

\begin{tabular}{|c|c|c|c|c|c|}
\hline Matrix & Method & $\begin{array}{l}\begin{array}{c}\text { Detection } \\
\text { limit }\end{array} \\
\end{array}$ & Linear range & Sensitivity & $\overline{\operatorname{Ref}}$ \\
\hline $\mathrm{NiO}$ nanorods & Cyclic voltammetry & $0.65 \mathrm{mM}$ & $0.64-10.3 \mathrm{mM}$ & $120 \mathrm{~mA} \cdot \mathrm{mM}^{-1}$ & 31 \\
\hline $\begin{array}{l}\text { NiO/CVD-grown } \\
\text { graphene }\end{array}$ & Chronoamperometry & $0.13 \mathrm{mM}$ & $2-40 \mathrm{mM}$ & $\begin{array}{c}40.6 \mathrm{~mA} \mathrm{mM}^{-} \\
1 \mathrm{~cm}^{-2}\end{array}$ & 32 \\
\hline Graphene/CD & $\begin{array}{c}\text { Differential pulse } \\
\text { voltammetry (DPV) }\end{array}$ & $1 \mathrm{mM}$ & $0.005-0.03 \mathrm{mM}$ & $\underset{1}{0.01} \mathrm{~mA} \mathrm{mM}^{-}$ & 33 \\
\hline $\mathrm{Ag} / \mathrm{CHOx} / \mathrm{Au} \mathrm{NPs} / \mathrm{SPE}$ & $\begin{array}{r}\text { anodic stripping } \\
\text { voltammetry (ASV) }\end{array}$ & $3.0 \mu \mathrm{g} / \mathrm{mL}$ & $5-5000 \mu \mathrm{g} / \mathrm{mL}$ & $\begin{array}{r}0.0610 \\
\mu \text { A.mL. } \mu^{-1} \\
\end{array}$ & 34 \\
\hline $\begin{array}{c}\text { Graphene/ } \beta- \\
\text { CD/Rhodamine } 6 \mathrm{G}\end{array}$ & Fluorescence & - & $0.005-0.03 \mathrm{mM}$ & $1 \mu \mathrm{M}$ & 35 \\
\hline Au-SPE/Pt/PDA-ChOx & Amperometry & $10.5 \mu \mathrm{M}$ & $35.3-500 \mu \mathrm{M}$ & $\begin{array}{l}14.3 \mathrm{~mA} \mathrm{M}^{-1} \\
\mathrm{~cm}^{-2}\end{array}$ & 36 \\
\hline ChOx/AuPt-Ch-IL/GCE & Amperometry & $10 \mu \mathrm{M}$ & $\begin{array}{c}0.05-6.2 \mathrm{mM} \text { and } 6.2- \\
11.2 \mathrm{mM} \\
\end{array}$ & 90.7 & 37 \\
\hline $\begin{array}{c}\mathrm{GCE} / \mathrm{CuO} \\
\mathrm{NPs} / \mathrm{PolyAN}+\mathrm{Mu}\end{array}$ & EIS & $0.10 \mu \mathrm{M}$ & $0.5 \mathrm{~nm}-50 \mathrm{mM}$ & $\Omega / \mathrm{M}$ & $\begin{array}{l}\text { This } \\
\text { work }\end{array}$ \\
\hline
\end{tabular}

CVD: Chemical vapor deposition technique

CD: cyclodextrin

SPE : Screen printed electrode

CHOx : Cholesterol oxidase

PDA : Polydopamine

Ch-IL: Iionic liquid-chitosan composite

Table 4: Cholesterol determination in milk samples.

\begin{tabular}{|l|l|l|l|}
\hline Samples & Added concentration $(\mathrm{mol} / \mathrm{L})$ & Measured concentration $(\mathrm{mol} / \mathrm{L})$ & Recovery $\%$ \\
\hline 1 & $10^{-8}$ & $1.2 \times 10^{-8}$ & 120 \\
\hline 2 & $2 \times 10^{-8}$ & $2.15 \times 10^{-8}$ & 107.5 \\
\hline 3 & $4 \times 10^{-8}$ & $4.26 \times 10^{-8}$ & 106.5 \\
\hline 4 & $6 \times 10^{-8}$ & $6.3 \times 10^{-8}$ & 105 \\
\hline
\end{tabular}

\section{Figures}



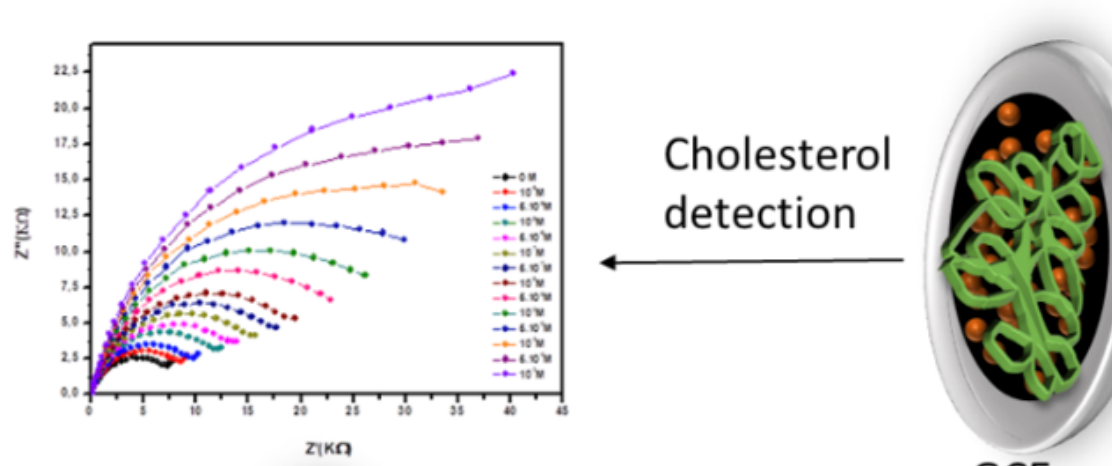

GCE
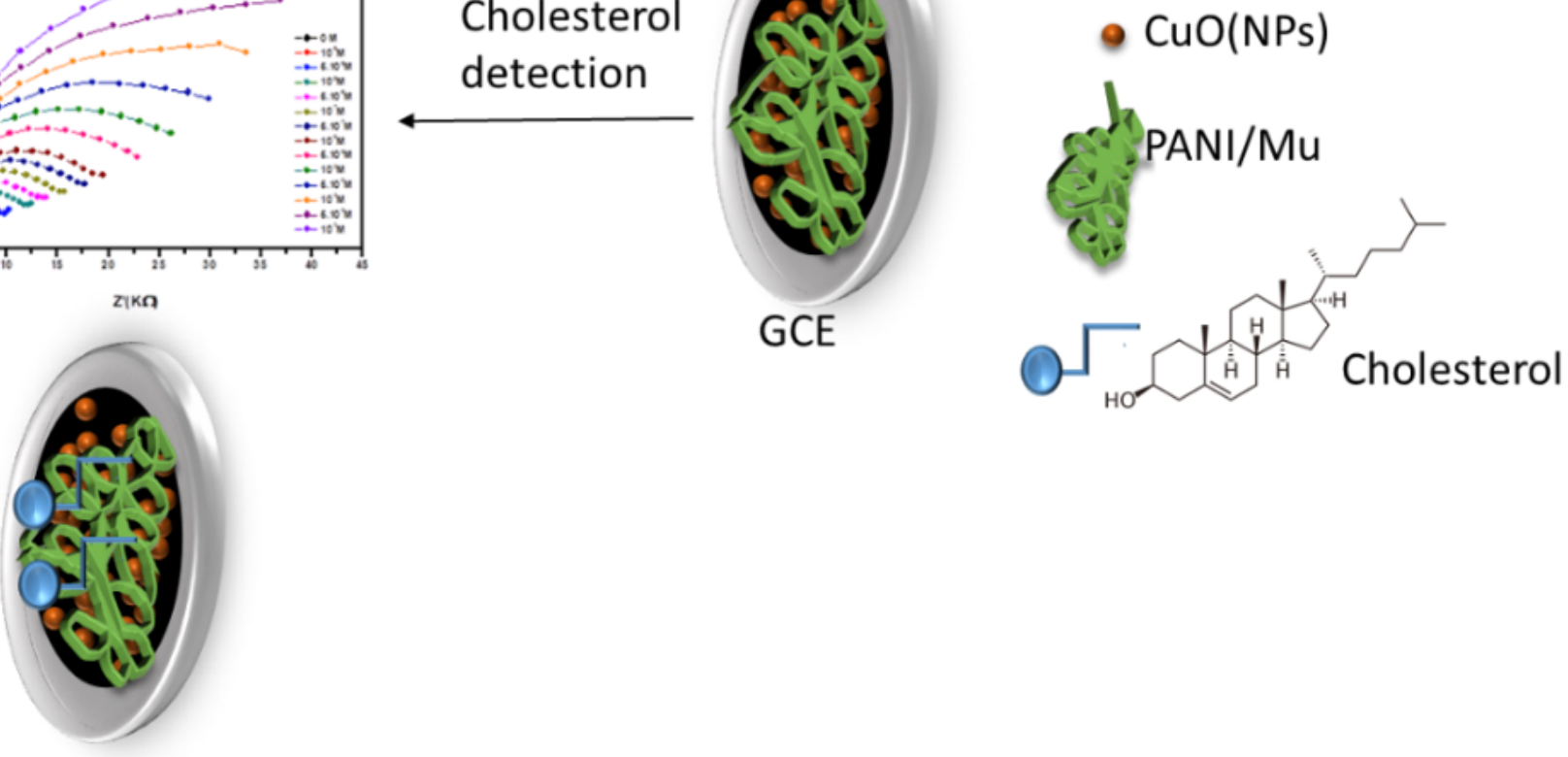

\section{Figure 1}

Schematic illustration of the experimental process during sensor fabrication.

(A)

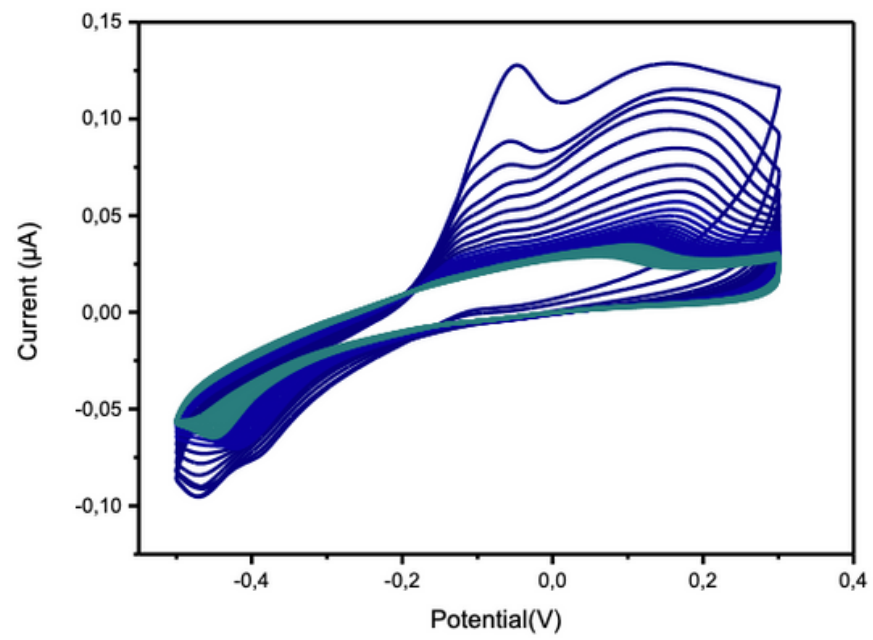

(B)

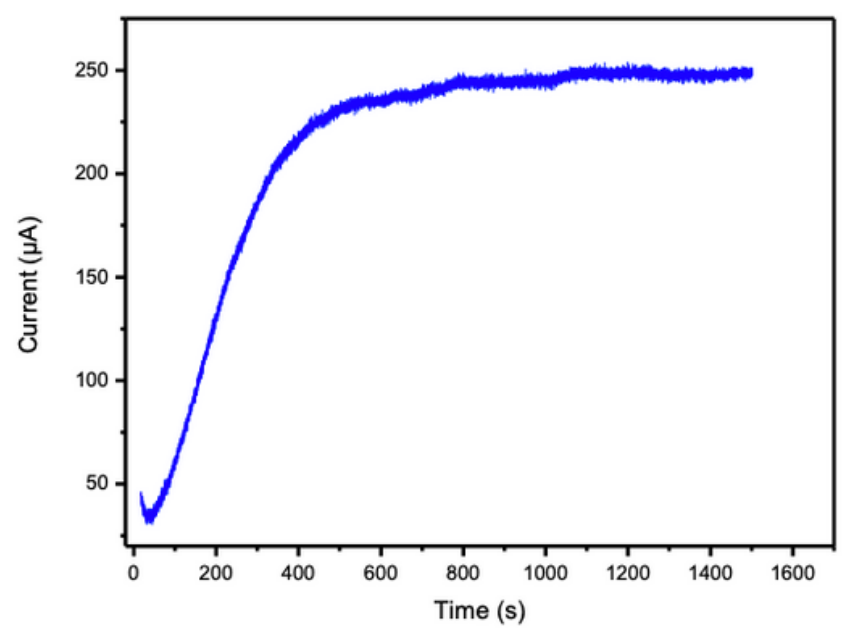

Figure 2

(A) Oxidation of copper nanoparticles by cyclic voltammetry in $0.1 \mathrm{M} \mathrm{NaOH}$ solution (40 cycles, $50 \mathrm{mV} / \mathrm{s}$ ) and (A) Chronoamperometry at $\mathrm{U}=0.85 \mathrm{~V}$ versus SCE for $1500 \mathrm{~s}$ in $1.00 \mathrm{M} \mathrm{H} 2 \mathrm{SO} 4$ solution containing 


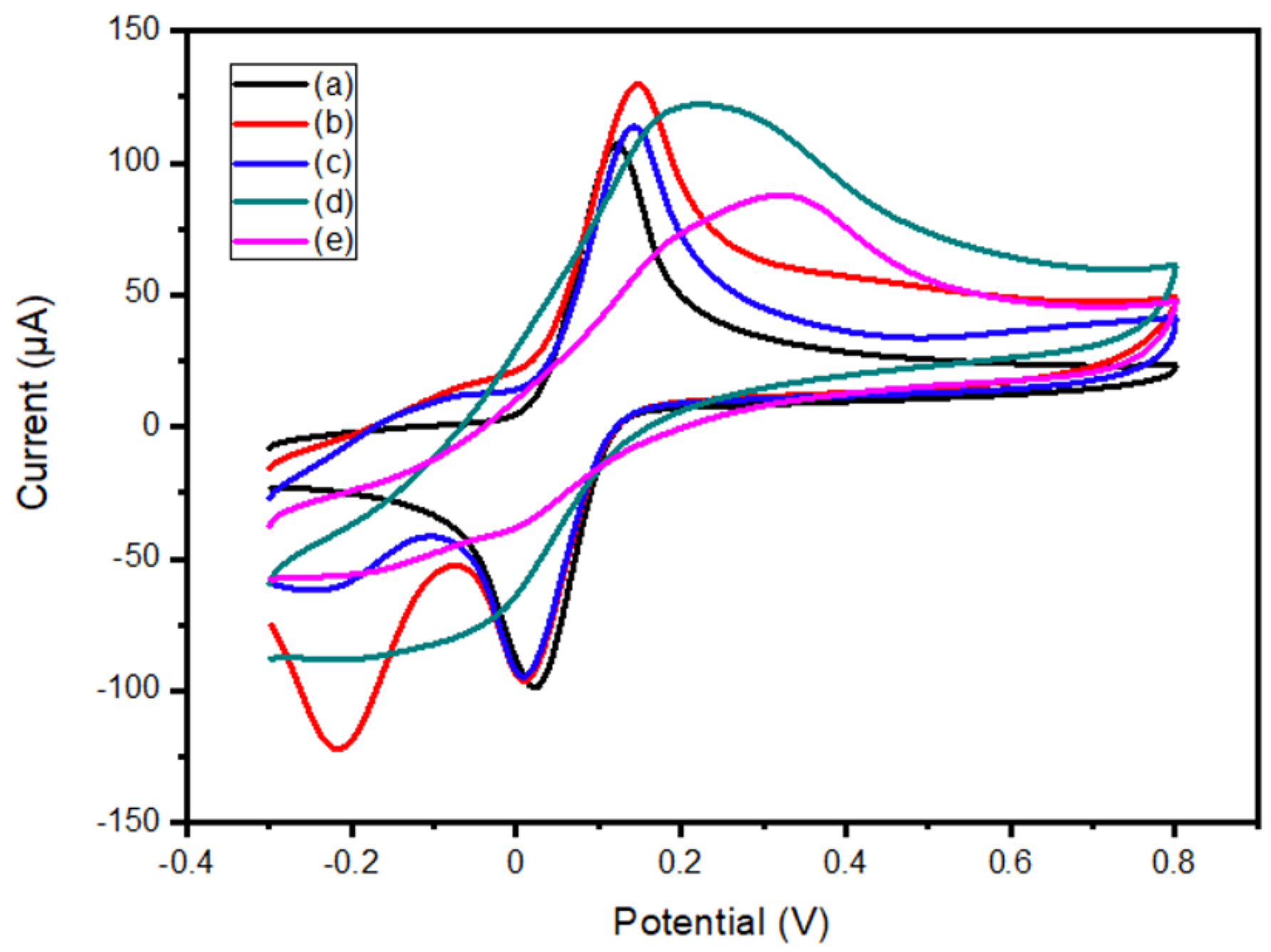

Figure 3

Cyclic voltammograms of different modified electrodes performed with hydroquinone 10-3M in $\mathrm{Pbs}$ $\mathrm{pH}=7,4$. At potential sweep rate of $100 \mathrm{mV} / \mathrm{s}$ vs. $\mathrm{Ag} / \mathrm{AgCl} /($ sat. $\mathrm{KCl}$ ). (a) Bare GCE, (b) GCE/Cu(NPs), (c) GCE/CuO(NPs), (d) GCE/CuO(NPs)/PANI and (e) GCE/CuO(NPs)/PANI/Mu. 
(A)

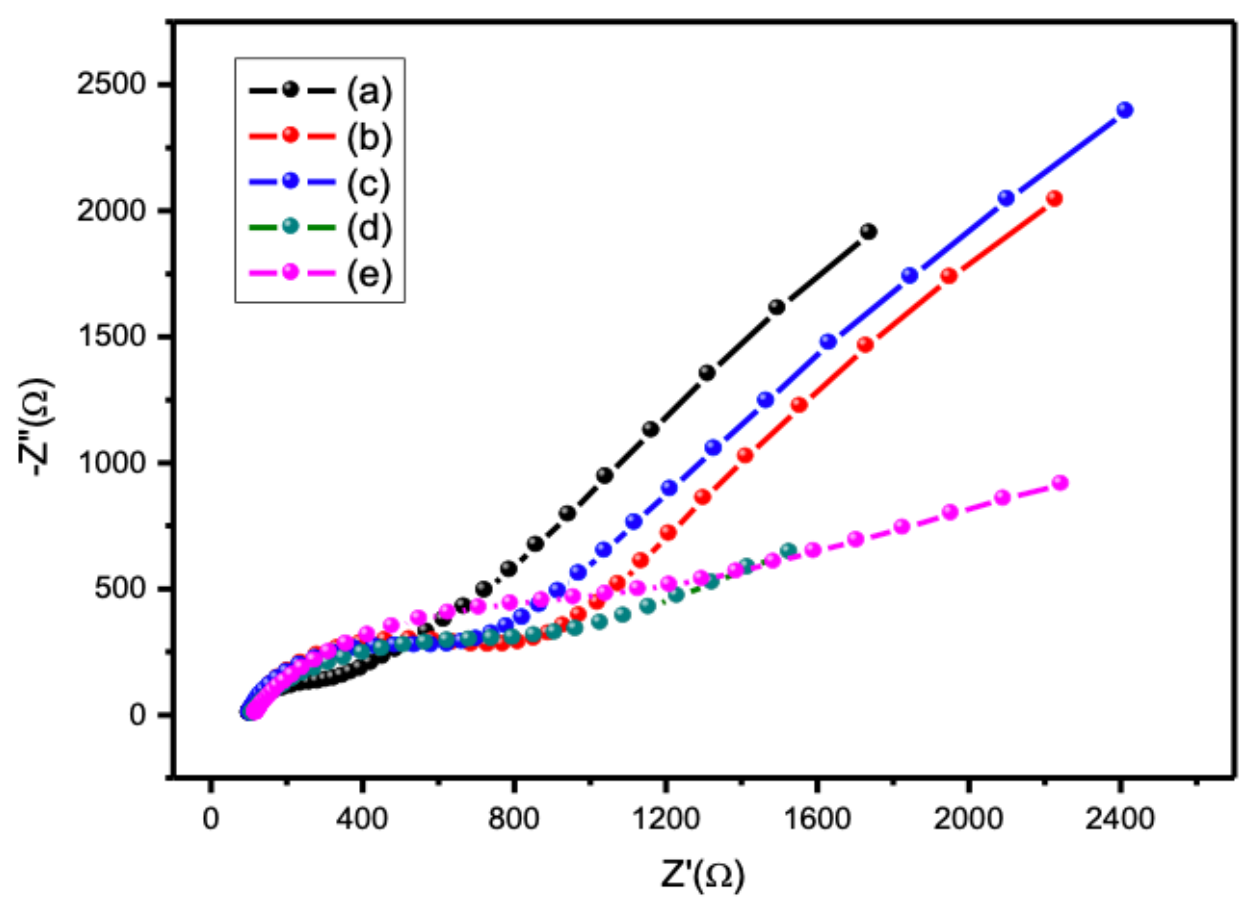

(B)

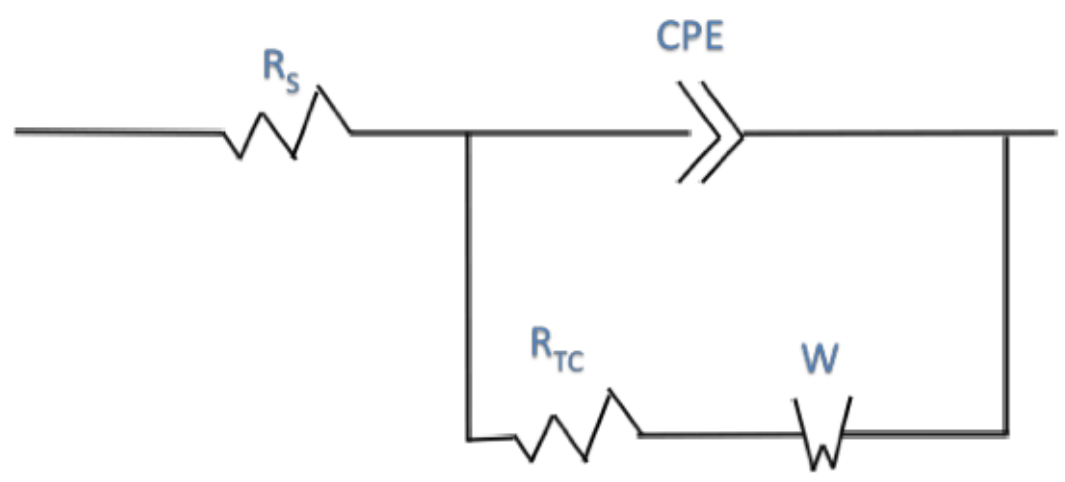

Figure 4

(A) Nyquist plots of the modified electrodes performed with hydroquinone (10-3M) in $\mathrm{Pbs} \mathrm{pH}=7.4$ solution. (a) Bare GCE, (b) GCE/Cu NPs, (c) GCE/CuO(NPs), (d) GCE/CuO (NPs)/PANI and (e) $\mathrm{GCE} / \mathrm{CuO}(\mathrm{NPs}) / \mathrm{PANI} / \mathrm{Mu}$. Frequency range is from 0.05 to $75,000 \mathrm{~Hz}$, the modulation amplitude is $10 \mathrm{mV}$ and the working electrode potential is $250 \mathrm{mV}$. (B) Randles-type equivalent circuit. 
A

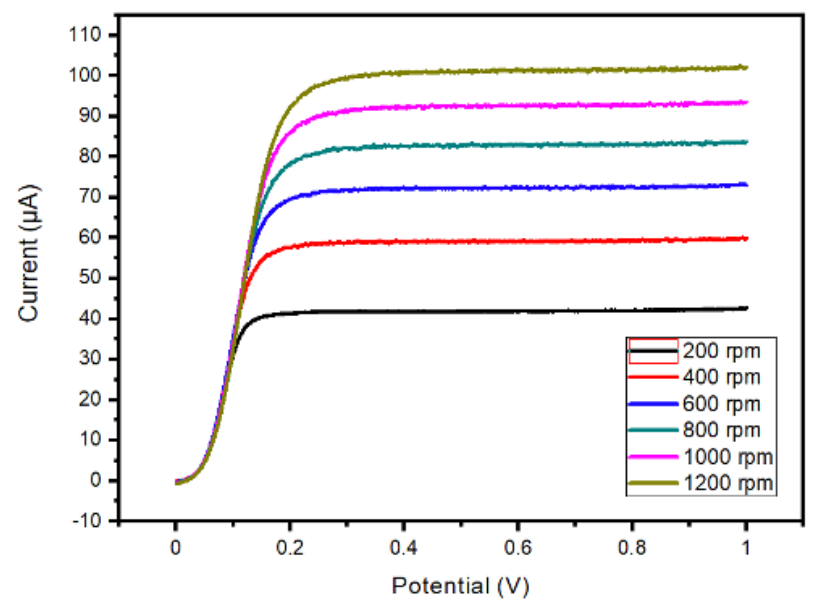

B

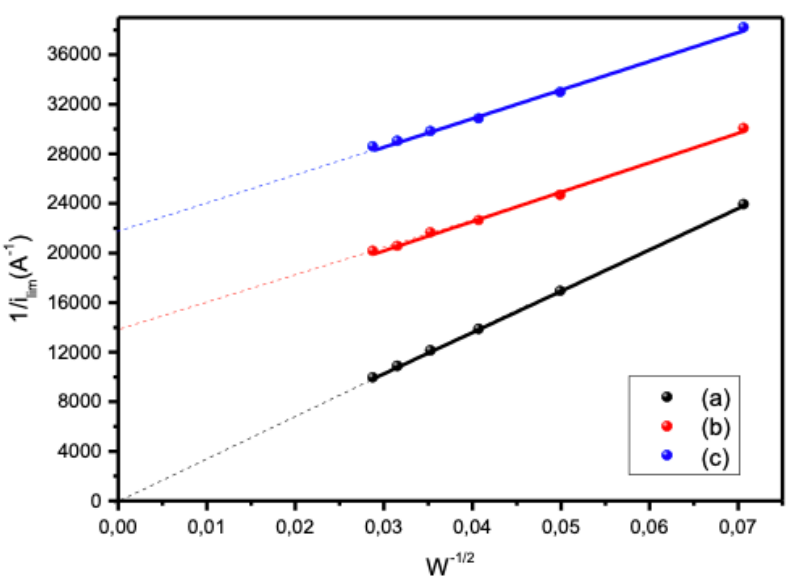

\section{Figure 5}

Spectrum of linear voltammograms (A) and Koutecky Levick characteristics (B) of (a) Bare GCE, (b) GCE/CuO(NPs)/PANI(c) GCE/CuO(NPs)/PANI/Mu (V = 10mV / s, $1 \mathrm{mM}$ Hydroquinone in phosphate buffer $\mathrm{pH}=7.4)$. 


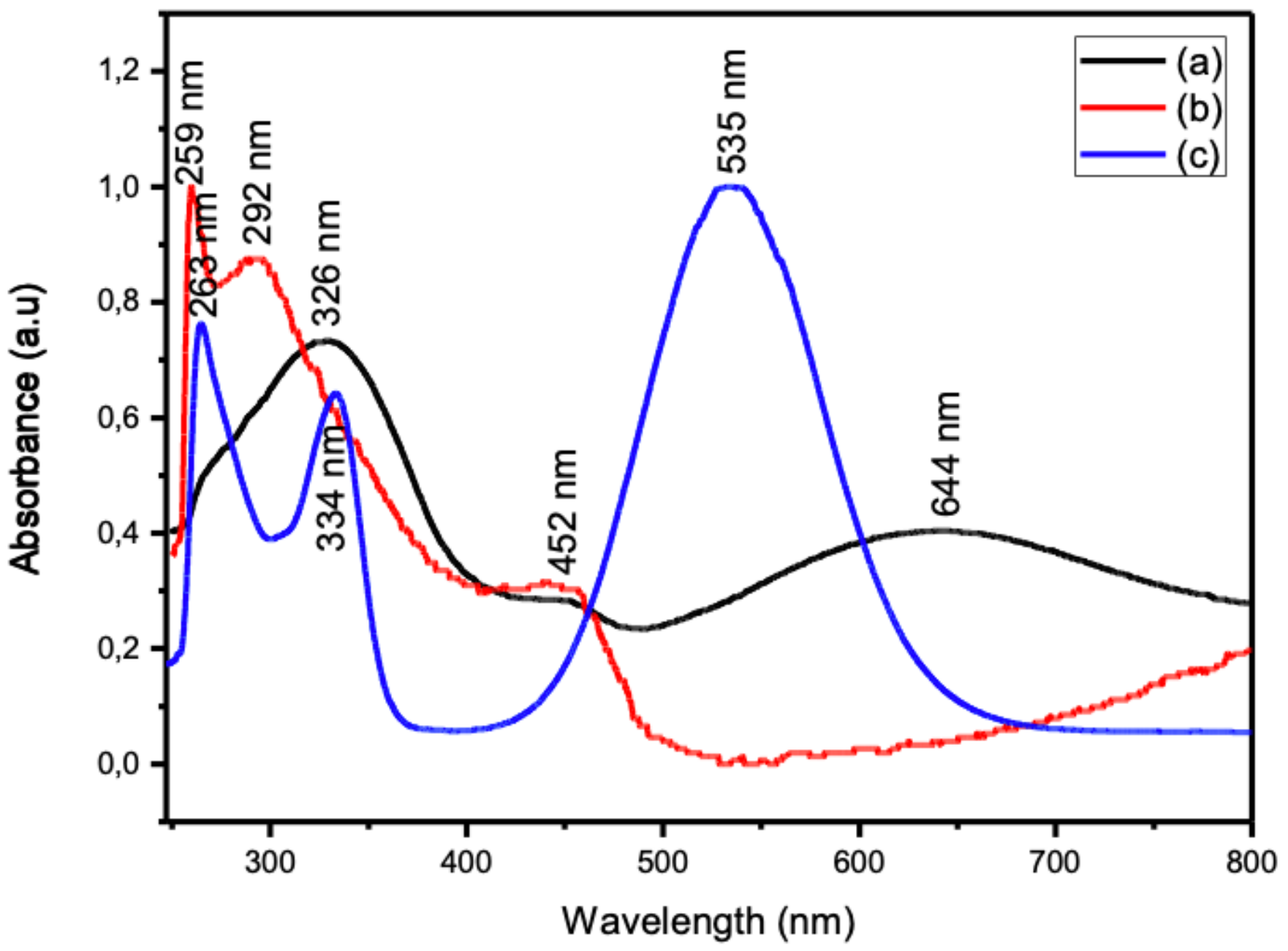

Figure 6

UV-visible spectra for (a) PANI, (b) CuO(NPs)-PANI-Mu-nanocomposite film and (c) Mu. 
(a)

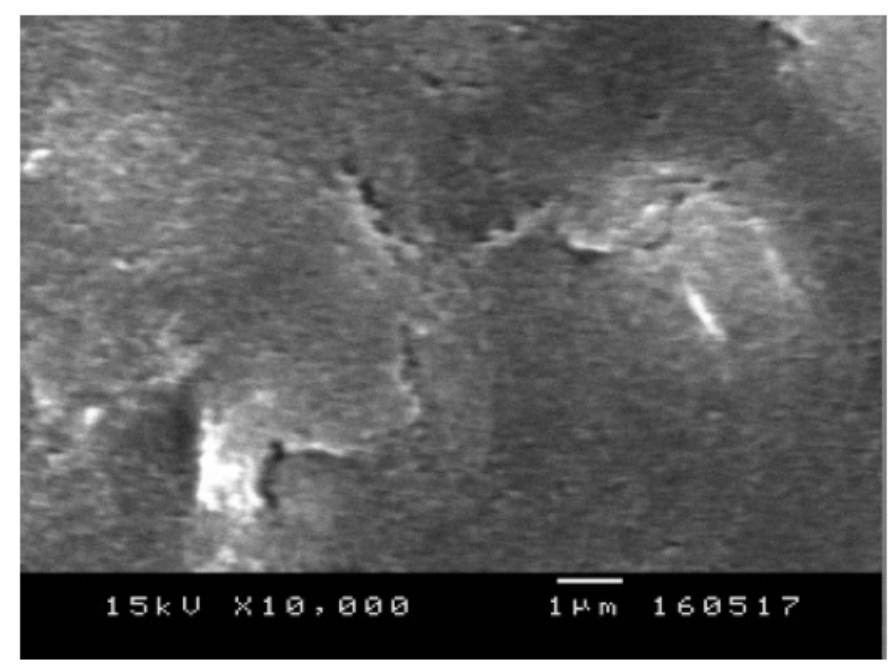

(c)

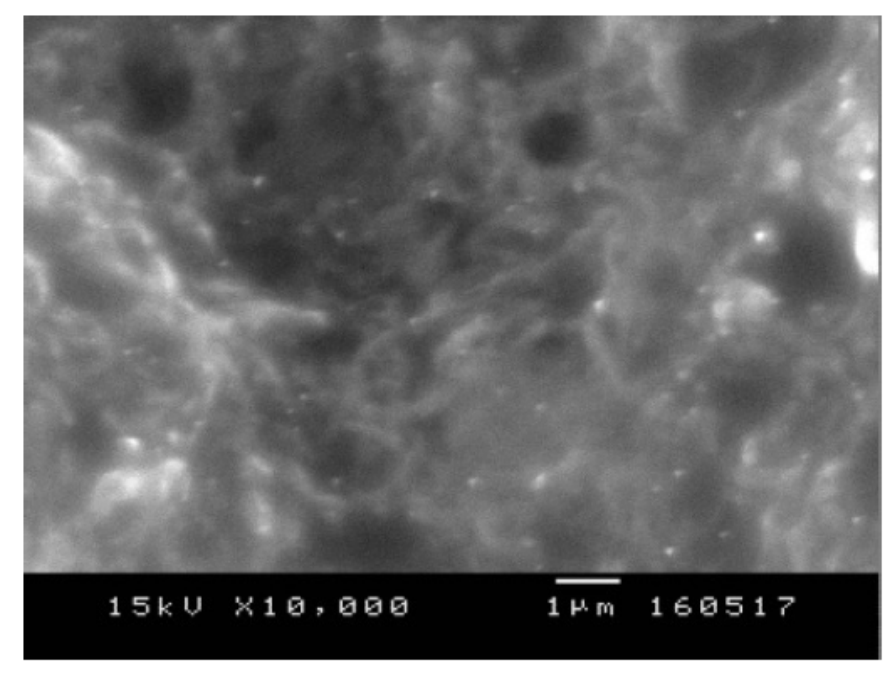

(b)

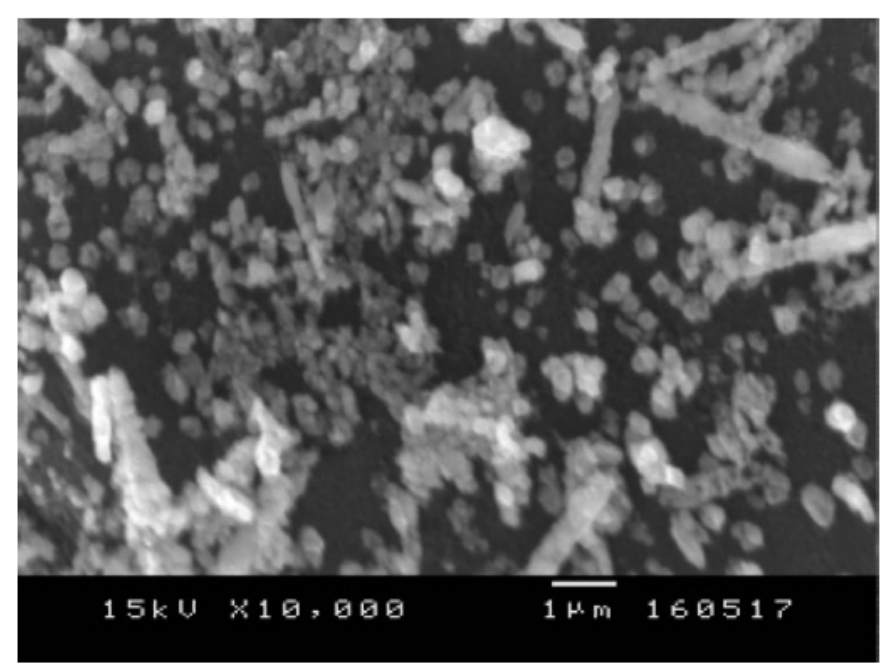

(d)

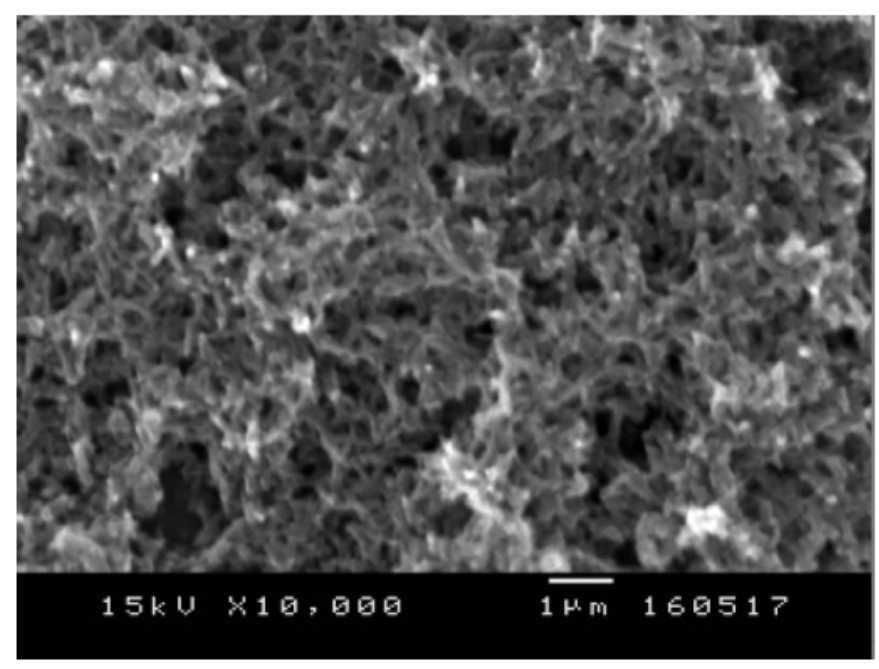

\section{Figure 7}

Scanning electron micrographs of (a) bare screen-printed carbon electrode (SPCE), (b) SPCE/CuO(NPs), (c) SPCE/CuO(NPs)/PANI and (d) SPCE/CuO(NPs)/PANI/Mu. Resolution of $1 \mu \mathrm{m}$, magnification of 10.000 and accelerating potential of $15.0 \mathrm{kV}$ were used. 


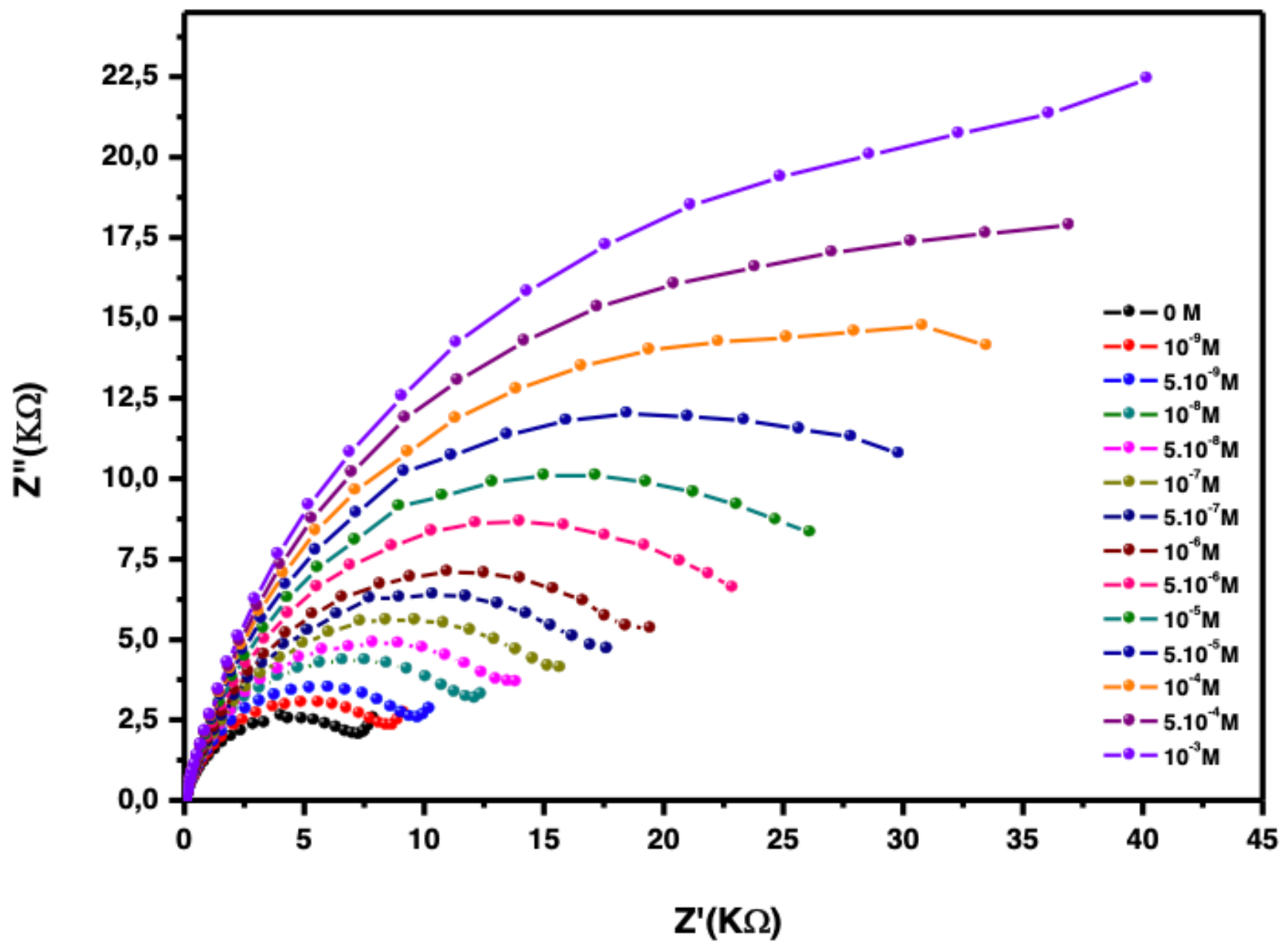

Figure 8

Nyquist diagrams corresponding to the detection of different concentrations of Cholesterol ranging from 10-9 to $10-3 \mathrm{M}$ in phosphate buffer solution $(100 \mathrm{mmol} / \mathrm{L}) \mathrm{pH}=7.4$ 


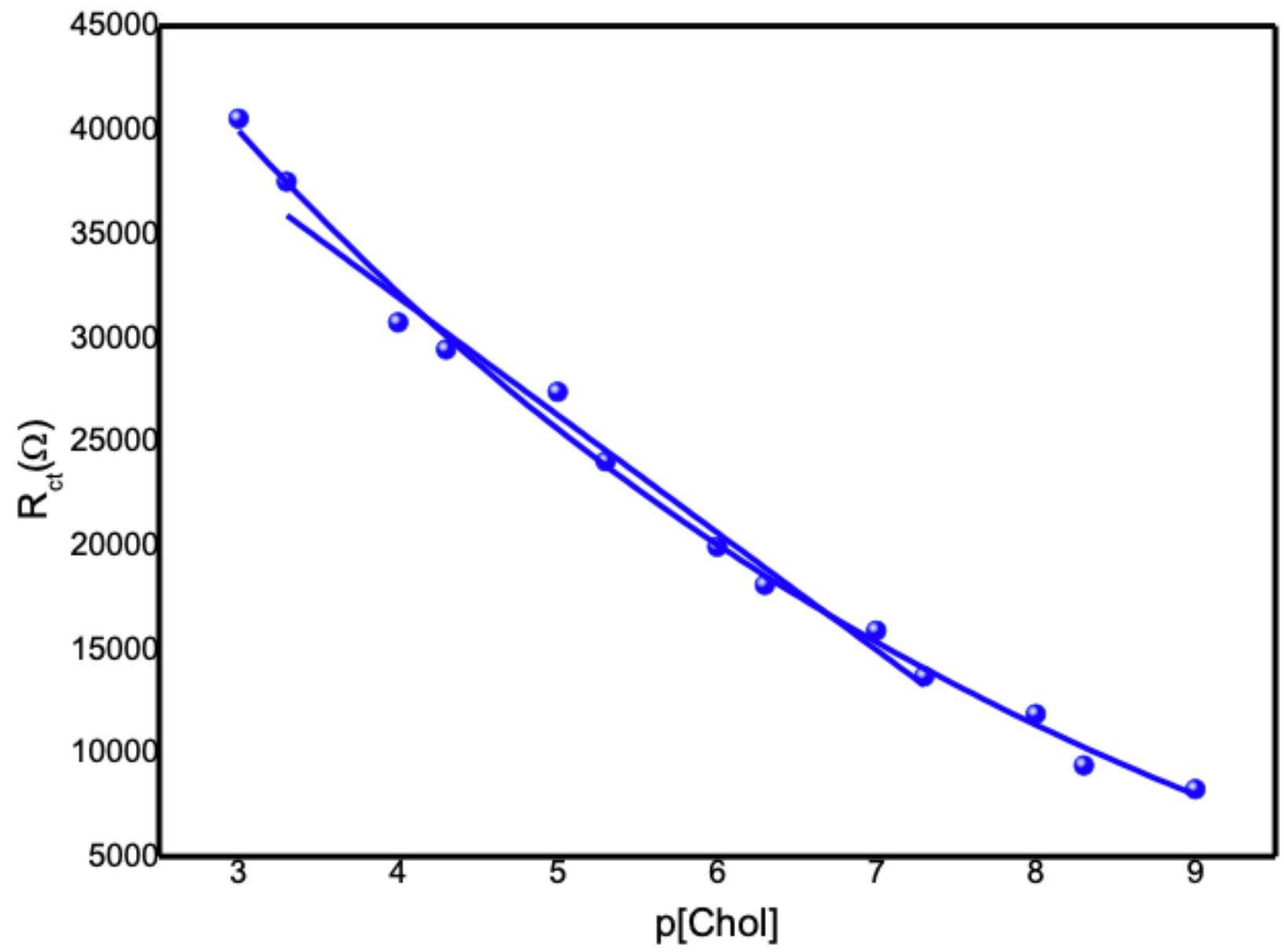

Figure 9

The linear relationship between Rtc and the negative logarithm of cholesterol concentration. 


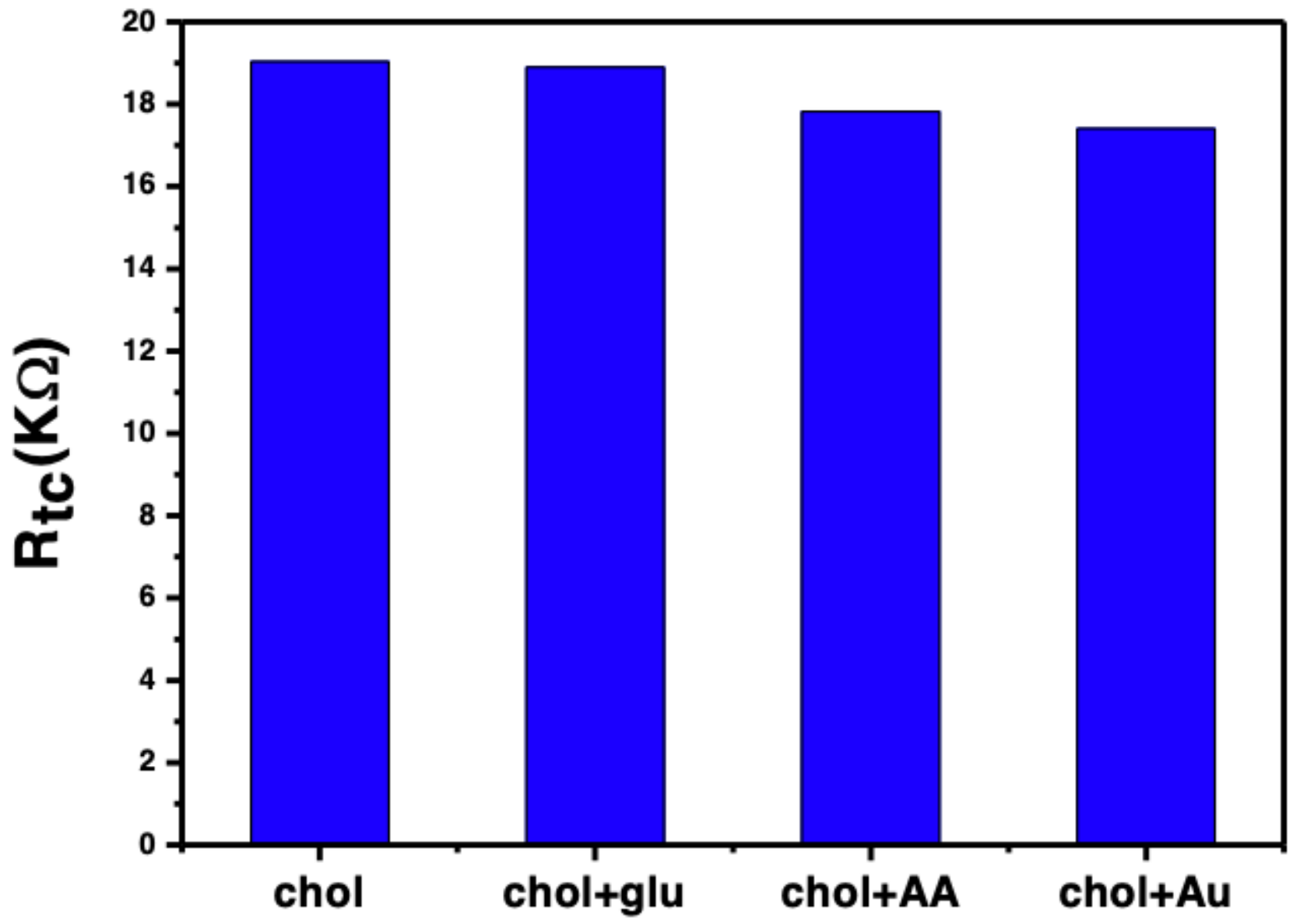

Figure 10

Interference effect on the charge transfer resistance. 